
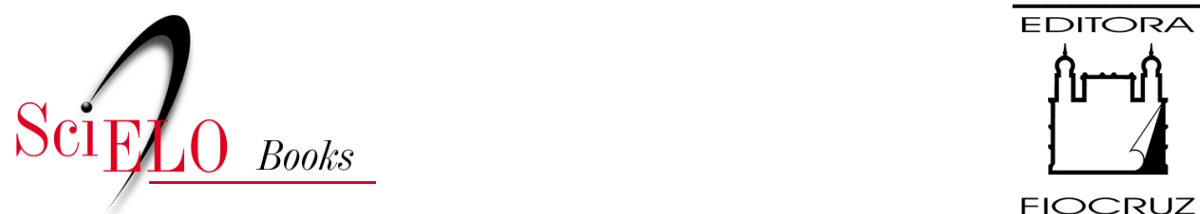

FIOCRUZ

\title{
1. Do homem ao laboratório a construção do conhecimento científico e da técnica na produção da vacina antivariólica
}

\author{
Tania Maria Fernandes
}

\section{SciELO Books / SciELO Livros / SciELO Libros}

FERNANDES, T.M. Do homem ao laboratório: a construção do conhecimento científico e da técnica na produção da vacina antivariólica. In: Vacina Antivariólica: ciência, técnica e o poder dos homens, 1808-1920 [online]. 2nd ed. rev. Rio de Janeiro: Editora FIOCRUZ, 2010, pp. 29-42. ISBN: 978-65-5708-095-5. https://doi.org/10.7476/9786557080955.0002.

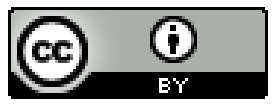

All the contents of this work, except where otherwise noted, is licensed under a Creative Commons Attribution 4.0 International license.

Todo o conteúdo deste trabalho, exceto quando houver ressalva, é publicado sob a licença Creative Commons Atribição 4.0.

Todo el contenido de esta obra, excepto donde se indique lo contrario, está bajo licencia de la licencia Creative Commons Reconocimento 4.0. 


\section{Do Homem ao Laboratório: a construção do conhecimento científico e da técnica na produção da vacina antivariólica}

A vacina antivariólica, que surgiu em fins do século XVIII, resultou da observação de Edward Jenner quanto ao fenômeno de 'proteção' contra a varíola, adquirida por algumas pessoas ao entrarem em contato com uma doença similar que acometia os bovinos, conhecida como cowpox. A observação desse fato em um grupo de ordenhadores o levou a desenvolver uma série de testes experimentais em pessoas sadias, com a finalidade de reproduzir esse fenômeno. ${ }^{1}$

Ao longo do século XIX, as experiências de Jenner foram aprofundadas e, a partir de meados do século, se incorporaram às investigações que marcaram a ciência biomédica do período. O conhecimento científico, nesse momento, em diversas áreas, adquiriu maior expressão por meio do aprimoramento do método experimental. Para a medicina, o desenvolvimento da fisiologia experimental tendo como expoente Claude Bernard, da microbiologia com Pasteur e da imunologia de Metchnikov, foi fundamental para o estabelecimento de uma nova base conceitual. Esses estudos, associados ao aprofundamento da biologia - que já vinha elaborando seu arcabouço teórico tendo como destaque as investigações em citologia realizadas por Virchow -, provocaram uma mudança significativa na medicina, que iria ter o laboratório como importante aliado de sua prática. 
Recentemente, vários estudos analíticos vêm buscando uma compreensão desse processo de mudanças na medicina do século XIX. Percebe-se um aprofundamento sistemático da questão por meio de diversos ângulos, estabelecendo-se um debate importante, com divergências principalmente quanto ao papel político da medicina e ao processo de consolidação da medicina com base experimental. ${ }^{2}$ No âmbito das mudanças que marcaram a medicina do século XIX, a varíola e a vacina antivariólica foram incorporadas por meio de estudos, em sua maioria europeus, voltados, sobretudo, para a identificação do agente da varíola e da vacina antivariólica e para a elucidação do 'mecanismo imunitário' que as envolve. Nesse momento, encontra-se em Pasteur uma das principais alusões com relação à vacina, especialmente no que diz respeito ao agente etiológico.

Embora existam muitas referências de Pasteur à vacinação, é preciso destacar, acompanhando o pensamento de Anne Marie Moulin, que a medicina pastoriana não construiu bases teóricas para a imunidade propriamente dita, preocupando-se, a princípio, em generalizar o conceito de imunização por meio da atenuação da virulência dos microorganismos. Segundo a autora, os seguidores de Pasteur buscavam, naquele momento, estabelecer um 'programa empírico de imunização' por meio do controle do desenvolvimento dos microorganismos em laboratório, sem se preocupar com o fenômeno de atenuação in vivo, que demandaria a necessidade de compreensão do fenômeno imunológico, só conquistada posteriormente (Moulin, 1991: 47).

Os avanços do conhecimento, no âmbito tanto da produção quanto da conceituação teórica, permitiram uma mudança substancial na compreensão dos mecanismos da vacina ao longo do século XX. Contrariamente ao que Jenner e Pasteur julgavam, compreendemos hoje o vírus vacínico como um 'produto artificial', decorrente da inoculação consecutiva do vírus do cow-pox ou da varíola em animais em laboratório. Para eles, a vacina tratava-se de um 'produto natural' pois era gerada na natureza. Uma vez introduzida no laboratório, com sua virulência controlada e purificada por processos físico-químicos, embora não fosse organicamente alterada, passou a ser entendida como 'artificial'. Apesar de Pasteur concordar com Jenner quanto à descrição da vacina antivariólica como um produto natural, é importante assinalar que houve mudanças bastante significativas na compreensão da vacina formulada pelos dois estudiosos. Com Pasteur essa definição assumiria um significado diferenciado, pois ele a incorporou à conceituação teórica que embasava a 
microbiologia então criada, relacionando-a à presença de um microorganismo.

A varíola e a vacina antivariólica, hoje, ao final de um intenso processo de investigação e de conquistas técnico-científicas - que proporcionaram a erradicação da doença -, são conhecidas, englobando um 'complexo' denominado 'varíola-vacínia' que as compreende como duas doenças similares. A doença ocasionada pela vacinação passou a ser conhecida como vacínia, tendo sido isolado um vírus denominado Poxvirus officinale, responsável pelas pústulas vacínicas, diferenciado do vírus causador da própria varíola (Bier, 1975; Angulo, 1982).

Como definição para a vacina antivariólica, afirma-se atualmente que: consiste em suspensão de tecidos animais, geralmente pele de vitela ou membrana corio-alantóide de embrião de galinha, contendo o vírus ativo (vivo) da vacínia. Esse vírus, o Poxvirus officinale é mutante, obtido no laboratório pela passagem seriada do vírus da varíola da vaca (cow-pox), ou ainda, do vírus da varíola humana, em pele de vitela e de coelho. (Angulo, 1982: 56)

\section{Jenner: a vacina ainda distante da microbiologia}

A descoberta da vacina antivariólica por Jenner aconteceu em conseqüência de suas observações, realizadas no fim do século XVIII, com relação à varíola e à imunidade causada no homem quando em contato com uma doença similar desenvolvida nos bovinos.

As experiências de Jenner vieram, na realidade, alterar uma prática bastante remota: a 'variolização', que teve sua origem provavelmente na China, tendo-se difundido na Europa a partir do século XVI. Essa técnica baseava-se na constatação de que os indivíduos que sobreviviam à varíola não mais a contraíam e que sua implantação artificial no organismo humano poderia provocar defesa contra a doença. A par dessa constatação, já se sabia que a varíola podia assumir uma forma benigna, conhecida como variolóide. Isso fez com que se desenvolvessem modelos de transmissão da varíola a partir dessa forma, julgando-se possível reproduzir a doença em sua expressão similar, igualmente benigna.

A ampla propagação da técnica de variolização, no entanto, acabou mostrando que esse processo permitia o desenvolvimento das diferentes manifestações da doença, independentemente da forma original, e sua 
aplicação atingia altos índices de mortalidade nos indivíduos inoculados. Cada inoculação poderia, na realidade, originar um doente, que, além de se expor aos riscos da varíola na sua forma confluente e letal, tornava-se um agente de difusão da doença. ${ }^{3}$

A descoberta de Jenner calcava-se não na tentativa de implantação da doença benigna, como ocorria com a variolização, mas, sim, na possibilidade de evitar a varíola do homem pelo contato com a doença, conhecida como cow-pox (pústula da vaca). Jenner observou que, ao cuidarem do gado portador da doença, os ordenhadores desenvolviam, nas mãos, pústulas idênticas ao cow-pox original, que, após alguns dias, murchavam e secavam. Constatou, também, que tais indivíduos não contraíam a varíola quando em contato com pessoas doentes. Reproduziu, então, sua observação (Jenner, 1798). A partir da pústula desenvolvida na vaca, obteve um produto que passou a denominar 'vacina', que, ao ser inoculado no homem, fazia surgir erupções, semelhantes à varíola, no local das inoculações. Dessas erupções era retirada a 'linfa' ou 'pus variólico', utilizado para novas inoculações. Formava-se, assim, uma cadeia de imunização entre homens, na qual o cow-pox da vaca funcionava como um primeiro agente imunizador. Essa vacina ficou conhecida como vacina jenneriana ou humanizada.

É preciso destacar que o conceito de imunidade, que explicaria o fenômeno da vacina, não havia sido ainda construído e que o instrumental responsável pela comprovação da hipótese de Jenner resumia-se na reprodução de fatos, observados anteriormente em condições naturais, pela inoculação em indivíduos.

Quanto a essa questão, acrescenta Darmon que Jenner jamais teria descoberto as propriedades do cow-pox se não tivesse procedido à inoculação, uma vez que ainda não se dispunha de uma referência teórica que possibilitasse a compreensão do processo imunitário ou que indicasse hipóteses a serem comprovadas empiricamente. Dessa forma, a experiência detinha-se em uma tentativa de reprodução da natureza (Darmon, 1986).

A vacina jenneriana foi recebida inicialmente com descrédito e receio - que acabaram sendo relativamente superados - e difundiu-se por todo o mundo, ao mesmo tempo em que novos estudos se somavam aos originais. Sua propagação se deu inicialmente entre os países europeus e logo em seguida chegou à América do Norte, alcançando o Brasil ainda nos primeiros anos do século XIX. ${ }^{4}$ Cerca de vinte anos depois de sua 
descoberta, percebeu-se que algum tempo após a inoculação, a vacina perdia seu efeito imunitário, proporcionando discussões e novas experiências, na tentativa de reativá-la. Em 1840, como resultado desse processo de investigação, recuperou-se o cow-pox original, tendo início uma nova etapa da imunização antivariólica, com a utilização da vacina retirada diretamente da pústula da vaca e inoculada no homem. Iniciava-se a era da 'vacina animal'.

Apesar do significativo avanço no controle da doença, obtido graças à descoberta das duas vacinas, existia um movimento contrário à utilização desse método profilático. Entre as justificativas antivacínicas, verifica-se a associação da vacina com outras doenças que poderiam ser transmitidas através da inoculação, principalmente da vacina humanizada. Surgia aí uma gama enorme de doenças passíveis de transmissão, sendo a tuberculose, a sífilis e a erisipela as mais expressivas. Quanto à sífilis, pôde-se mais tarde comprovar a possibilidade de sua transmissão através da vacina, o que contribuiu, significativamente, para o desuso da vacina humanizada.

Não obstante a comprovação de sua eficácia, a vacina animal demorou mais de vinte anos para difundir-se fora de seu país de origem. Restringiu-se à Itália até 1864, quando foi apresentada no Congresso Médico de Lyon, que serviu como fórum propagandista da vacina animal. Gabiati e Nigri discutiram os resultados de suas experiências com a vacinação em Nápoles, tendo sido aprovada e, a partir daí, difundida em outros países, chegando ao Brasil somente em 1887.

A demora na difusão da vacina animal nos países europeus decorreu, sobretudo, do receio, tanto técnico como moral, do uso de um produto terapêutico extraído da vaca. Afirmava-se, na época, que a inoculação da vacina 'avacalharia' as pessoas, transplantando-lhes características do animal, além de transmitir doenças próprias dos animais para os indivíduos inoculados.

No Brasil, além dessas justificativas, percebemos que a carência de uma formação científica institucionalizada ao longo do século XIX dificultou a importação dessa técnica, que requeria procedimentos específicos de produção e conservação.

A clássica caricatura intitulada The cow-pock or the wonderful effects of the new inoculation! (1802), de James Gillray, mostra uma das interpretações das conseqüências da vacinação (Figura 1). 
Figura 1 - The cow-pock or the wonderful effects of the new inoculation! (James Guillray, 1802). National Library of Medicine, Bethesda, EUA

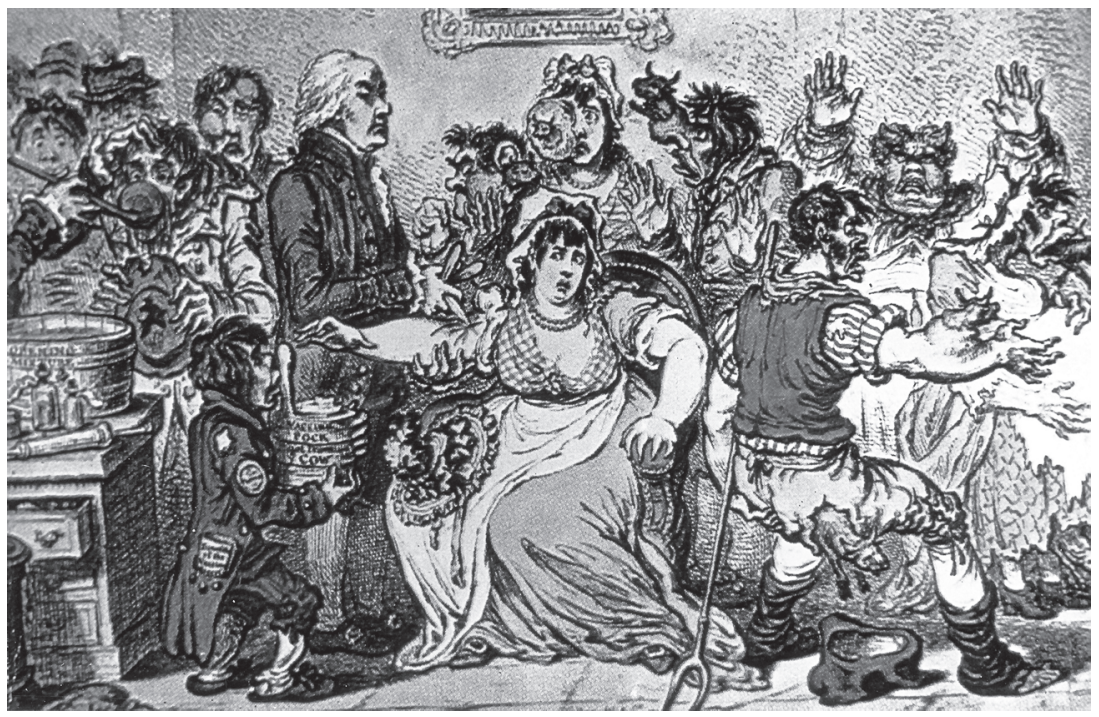

No Brasil, além dessas justificativas, percebemos que a carência de uma formação científica institucionalizada ao longo do século XIX dificultou a importação dessa técnica, que requeria procedimentos específicos de produção e conservação.

Somente na virada do século XIX é que o Brasil começaria de forma mais sistemática a produzir conhecimentos no âmbito da medicina com base experimental, a partir, principalmente, da criação de institutos de pesquisa e produção de imunoterápicos, destacando-se os do Rio de Janeiro e de São Paulo.

\section{Vacina Animal: avanços na experimentação}

A mudança na técnica de produção da vacina antivariólica, a partir de 1840, eliminando o homem como seu 'instrumento', é a diferença básica observada entre as duas vacinas - jenneriana e animal -, pois conceitualmente têm a mesma lógica: uma doença produzindo imunidade para outra semelhante. A vacina de origem animal consiste, na realidade, numa mudança técnica da vacina de Jenner, uma vez que é igualmente produzida a partir do cow-pox. 
Não se conheciam, ainda, o agente etiológico da doença nem o princípio do processo imunizante. Assim, a eficácia da técnica de vacinação só podia ser comprovada por meio de verificações estatísticas, que indicavam que a vacina animal possuía maior atividade do que a humana. Além disso, era descrita como de aplicação menos agressiva, pois se eliminava a fase de extração da linfa no homem, narrada como extremamente dolorosa.

A utilização da vacina de origem bovina, no entanto, não resolveu o problema da limitação do tempo da ação vacinal, comprovando-se a perda do poder imunizante ao longo de determinado período. A defesa contra a doença é temporária, tanto na vacina humanizada como na de origem animal. A nova vacina solucionou, porém, a questão da desativação do vírus da vacina humanizada, que se dava pela passagem progressiva de 'braço a braço', conforme pôde ser comprovado posteriormente. Como solução para o problema das duas vacinas, passou-se a indicar a revacinação periódica a partir da primeira inoculação, o que provocou grandes polêmicas e questionamentos. Se já era difícil convencer a população a vacinar-se, mais complexo tornava-se o convencimento no caso da revacinação, entendida como uma indicação de falha técnica na aplicação da primeira dose.

Amplas discussões foram travadas no âmbito acadêmico e político, sendo publicados inúmeros trabalhos sobre a questão, principalmente na Europa. As idéias mais significativas eram 'importadas' para o Brasil e reproduzidas em publicações e discursos brasileiros. ${ }^{5} \mathrm{O}$ investimento expressivo em pesquisa no país tomaria impulso somente nos primeiros anos desse século.

Alguns defensores da vacina, tentando o convencimento público para a prática da revacinação, buscaram em Jenner sua justificativa (Guarany, 1863: 480). Equivocaram-se, porém, ao afirmar que o mentor da vacina indicava a revacinação periódica, pois a imunização temporária proporcionada pela vacina só foi percebida após sua descoberta. Jenner indicava a revacinação até que se pudesse comprovar a 'pega' da vacina, não a enunciada como dose de reforço, como percebido posteriormente. Na realidade, tratava-se de duas justificativas diferentes aplicadas a um mesmo termo: por um lado, era a indicação de uma segunda dose de vacina para se comprovar a eficácia de sua aplicação; por outro, apontava-se a revacinação como reforço, realizada alguns anos depois da primeira dose. 
Além da busca da legitimação em Jenner para a revacinação, distinguimos uma questão conceitual, envolvida na polêmica, que se instalou devido à diferença fundamental entre palavras e conceitos. Observamos aqui a alteração de determinados conceitos referentes a termos já utilizados. O termo 'revacinação' soma-se a outros, como 'vírus', 'virulência', 'linfa', que continuaram a ser utilizados, adquirindo, porém, novos significados. 'Vírus', por exemplo, referia-se ao veneno que se julgava estar presente em algumas doenças, passando a ser utilizado para designar o agente etiológico, antes de haver condições técnicas de isolá-lo e visualizá-lo. Nessa nova concepção, o termo 'vírus' englobava um grupo de microorganismos com características semelhantes. O termo 'virulência' indicava a força do vírus, assumindo com Pasteur um significado fundamental que deu suporte à teoria microbiana a partir da descoberta da possibilidade de controle da virulência (do poder) dos microorganismos. 'Linfa', outro termo bastante utilizado, aplicava-se ao líquido extraído da pústula vacinal, sendo hoje empregado para referir-se ao líquido produzido no organismo e que circula nos vasos linfáticos.

Ainda nesse período, outros termos e conceitos tiveram relevância. O que Jenner considerava ser apenas uma doença semelhante à varíola, porém mais branda e com expressão localizada, com pústulas no local da inoculação e capacidade de proteger o indivíduo contra a varíola, mais tarde veio a ser considerada como resposta imunizante, sustentada por complexa conceituação teórica. Com relação à eficácia da vacina, era usual utilizar os termos 'verdadeira' e 'falsa', associando-se à primeira uma idéia de resposta 'constitucional', isto é, que comprometesse todo o organismo em sua constituição e não produzisse somente uma reação local. Ainda associada à idéia de eficácia da vacina, utilizava-se o termo 'falência' da vacina, atribuindo-a a diversas causas que envolviam os procedimentos do vacinador, questões técnicas como uso de lanceta enferrujada, ação do ar e influência do clima (Academia Real das Ciências de Lisboa, 1812; Monteiro, 1887a).

A idéia central, introduzida por Jenner, de que a vacina antivariólica produzia uma doença foi, como já destacamos, acatada por Pasteur. Segundo essa idéia, não era o vírus da varíola que estava presente na vacina e, sim, um vírus similar modificado pela disseminação no gado bovino. Apesar de partidários de uma mesma compreensão da vacina - como uma doença -, existem diferenças bastante profundas no entendimento que os dois assumiram sobre esse processo, que, para Pasteur, justificava-se 
pela presença de um agente etiológico específico, cuja ação era passível de controle.

\section{Vacina: uma importante questão para o laboratório}

Apesar de coincidir com o início das pesquisas desenvolvidas com utilização do método experimental, a introdução da vacina animal para proteção à varíola não está intimamente relacionada às concepções que seriam geradas nesse contexto do conhecimento médico. Acreditamos que o retorno ao cow-pox e à utilização da vacina antivariólica animal não foi uma decorrência do movimento pela medicina de base experimental. Na realidade, foi o resultado de um processo de aperfeiçoamento técnico do poder de imunização da vacina antivariólica que reproduzia os fatores constatados por Jenner.

Posteriormente, a introdução da microbiologia, em um primeiro momento, alterou - e teve grande significado para a vacina antivariólica - o conceito de vacina, associando a existência de um microorganismo a uma resposta imunitária. Apesar da não elucidação do processo imunitário, nesse momento, acrescentou-se a idéia de 'virulência' controlada, fundamental para a nova ciência, podendo-se atenuar ou potencializar a ação do microorganismo. Introduziu-se, ainda, o conceito de 'vírus-vacina', que seria “o vírus que causa a doença e não a morte, preservando da ação do vírus mortal, seguindo a lei geral da não recidiva das doenças virulentas" (Vallery-Radot, 1922, VI: 339; Portocarrero, 1991).

Para Pasteur, a vacina antivariólica era indicada como uma doença em sua forma mais branda. Afirmava ele:

A vacina jenneriana é um vírus que produz uma doença benigna; uma vez que a tivemos, ela preserva de uma doença mais grave, freqüentemente mortal, que é a varíola, (...) não é um produto de laboratório, é um produto natural; ele provém, como todo o mundo sabe, de uma doença própria da vaca e do cavalo. (ValleryRadot, 1922, VI: 258)

O laboratório para a vacina antivariólica funcionaria como um espaço essencial de controle, principalmente da 'virulência' da vacina, por meio de ações físico-químicas. Ao passar pelo laboratório, essa 'doença' seria controlada - atenuada ou potencializada. 
Para Anne Marie Moulin, a virulência seria interpretada pela medicina pastoriana, excluindo-se o fenômeno imunológico propriamente dito, que só seria analisado posteriormente. Essa autora considera a imunidade como um ponto fraco das teorias microbianas e estabelece ainda uma distinção entre a 'imunologia', como uma ciência autônoma, posterior a Pasteur, e a 'vacinologia', como denomina a prática ligada à vacina e que engloba desde a organização industrial da produção até a vacinação. Ressalta também a diferenciação entre a imunização, como um conjunto de técnicas, e a ciência da imunidade, referenciada em conceitos teóricos próprios (Moulin, 1991). A mesma autora acrescenta ainda que "a vacinologia é hoje uma ciência em vias de autonomia” (Moulin, 1996: 41).

A vacina continuou a ser produzida em grande escala preferencialmente em vitelos, apesar de várias pesquisas tentarem levar sua produção para meios de cultura, embrião de galinha ou mesmo outros animais, principalmente o coelho. O aprofundamento teórico e experimental presente nos últimos anos do século XIX proporcionou alterações no âmbito da técnica de produção da vacina, introduzindo alguns procedimentos na etapa posterior à retirada da secreção das pústulas do vitelo. Agentes físicos e químicos foram indicados para purificação, atenuação e conservação. Buscava-se, com isso, o domínio sobre o imunoterápico fora do organismo humano, que passou a não ser mais considerado o único meio de experimentação e, sim, de aplicação terapêutica depois de comprovada a eficiência em cobaias ou in vitro. ${ }^{6}$

A partir desse momento, percebemos também experiências com relação à varíola e seu imunoterápico, que se dirigiram no sentido da elucidação do agente etiológico, da purificação da vacina, da simplificação de sua técnica de produção, da compreensão do processo imunológico, da fisiopatologia e da terapêutica. Um dos primeiros avanços nesse sentido, em relação à vacina antivariólica, ocorreu em Berlim, em 1886, com a introdução da glicerina como uma substância purificadora e conservadora para o imunoterápico, que se tornou de uso universal. Essa descoberta, de grande valia, resultou da comprovação de que a vacina continha restos celulares, líquidos orgânicos e outros microorganismos que precisavam ser eliminados ou controlados.

Quanto aos microorganismos encontrados na vacina e na secreção variolosa, pensou-se, inicialmente, em uma relação de simbiose entre seus agentes (vírus vacínico e variólico) e algumas espécies bacterianas 
(estreptococo ou estafilococo), sendo entendidos como agentes múltiplos das duas 'doenças' - varíola e vacina.

A discussão sobre a possível simbiose entre os microorganismos estendeu-se até a primeira década do século XX, quando pôde ser comprovada a capacidade dos vírus da varíola e da vacina de atravessarem os poros diminutos de velas de filtração, o que outros germes não conseguiam. O material obtido por filtração manteve a mesma virulência do líquido original, porém excluiu os demais germes, até então associados à doença e à vacina. A manutenção da virulência do filtrado permitiu suprimir a idéia da simbiose entre vírus e bactérias como característica da doença e da vacina. Essa descoberta abriu dois caminhos de investigação: o isolamento do vírus e o papel das bactérias, sempre encontradas nas pústulas vacínicas e variólicas.

No Brasil, o Instituto Oswaldo Cruz, por meio das pesquisas de Henrique Aragão e do cientista Prowazek - que viera da Alemanha a convite de Oswaldo Cruz -, participou dessa discussão, realizando trabalho sobre o caráter da filtrabilidade do vírus variólico na tentativa de identificação do agente etiológico da doença. Em 1907, acreditaram que haviam isolado, a partir do filtrado, o agente da doença. Caracterizaramno como um protozoário, publicando o resultado da pesquisa em revista alemã e nas Memórias do IOC, além de comunicar a descoberta em sessão da Academia de Medicina (Prowazek \& Aragão, 1908; Cruz, 1909). Essa descoberta foi também anunciada por meio de jornais, em alguns sob a forma de charge, como a reproduzida na Figura 2. Note-se que tal imagem aponta a Europa curvando-se ao Brasil e Oswaldo Cruz como autor da descoberta.

Posteriormente, descobriu-se que não se tratava do micróbio da varíola, porém o poder de filtração (filtrabilidade) indicado nessa experiência passou a ser utilizado como um meio físico de purificação da vacina extremamente eficaz.

A presença de bactérias - comum nas infecções purulentas - foi profundamente estudada, elucidando-se o papel desses microorganismos como responsáveis pela fase de supuração da varíola e da vacina, e não como agentes da doença. A partir dessa descoberta, buscaram-se terapêuticas medicamentosas e sorológicas para o controle dessa fase da doença, que passou a ser entendida como uma infecção secundária, oportunista. O uso do permanganato de potássio como antibacteriano mudou substancialmente o quadro clínico da doença. 
Figura 2 - Gloria ao Brasil ! O Malho (17/07/1909)

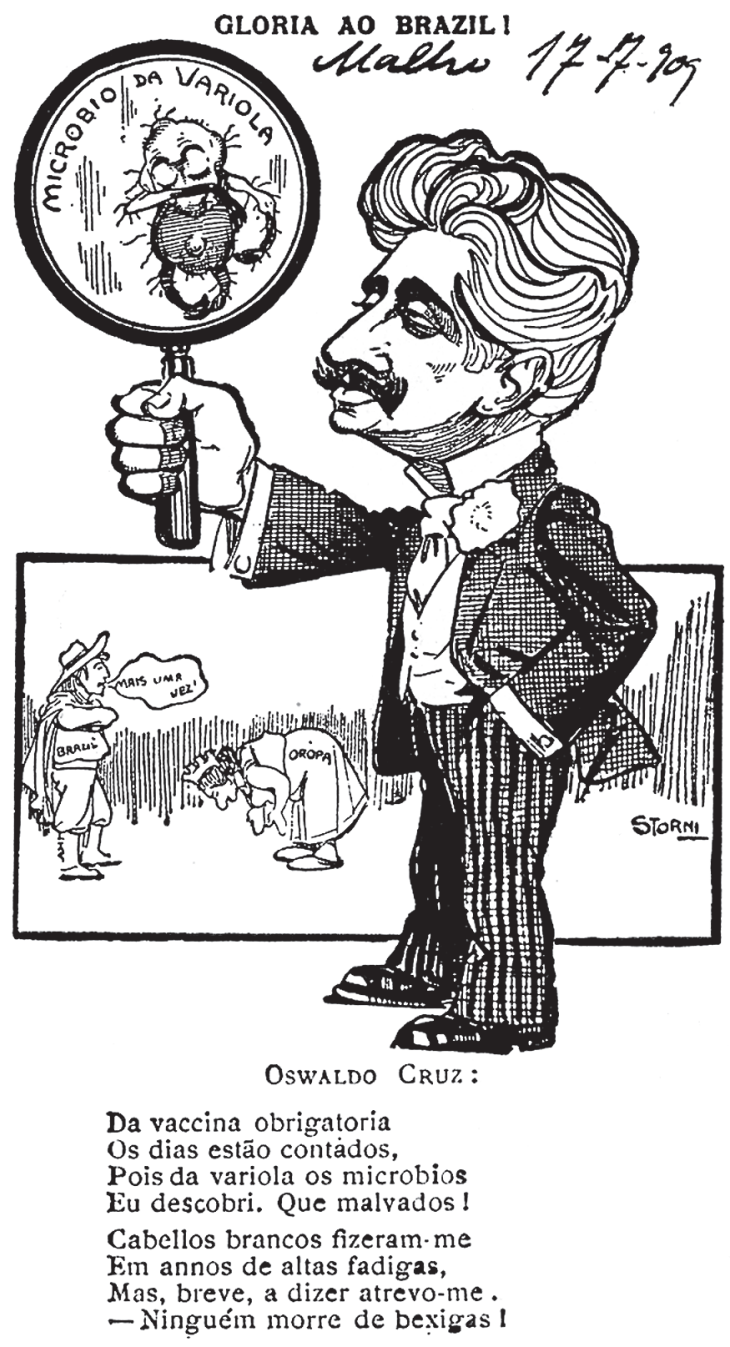

Fonte: Falcão (1971).

Ainda com relação à identificação dos agentes da varíola, da vacina e do cow-pox, várias experimentações foram realizadas. Em 1892, Guarnieri identificou os corpúsculos que levam seu nome, afirmando tratar-se do agente da varíola e da vacina. Mais tarde, foram definidos como fenômenos de degeneração celular, sendo interpretados, graças ao aprimoramento das técnicas microbiológicas, como 'inclusões intracitoplasmáticas' (Bachmann, 1910; Bier, 1975). 
Sobre o cultivo do vírus (variólico e vacínico) em cobaias e meios de cultura, várias foram as tentativas experimentais. Em 1889, foi detectada a receptividade do coelho para esses vírus, contando-se com trabalhos de Calmette, Guérin, Noguchi e Levaditi. A técnica de cultura de tecidos para o cultivo do vírus vacínico foi introduzida somente em 1925, por Pasker e Nye. Já a cultura do vírus vacínico em ovo embrionado surgiu em 1931 com os trabalhos de Goodpasture, sendo de extrema importância para a produção do imunoterápico.

Apesar de todos os estudos para modernizar a técnica de produção da vacina antivariólica, buscando-se outros meios de cultivo (principalmente o ovo embrionado) e seguindo-se a técnica utilizada para a fabricação da vacina contra a febre amarela, continuou-se a produzir no Brasil, em larga escala, a vacina em vitelos.

Na imagem a seguir (Figura 3), observa-se um laboratório de produção da vacina antivariólica em vitelos.

Figura 3 - Foto de laboratório de vacina animal. Manguinhos, Rio de Janeiro (s.d.)

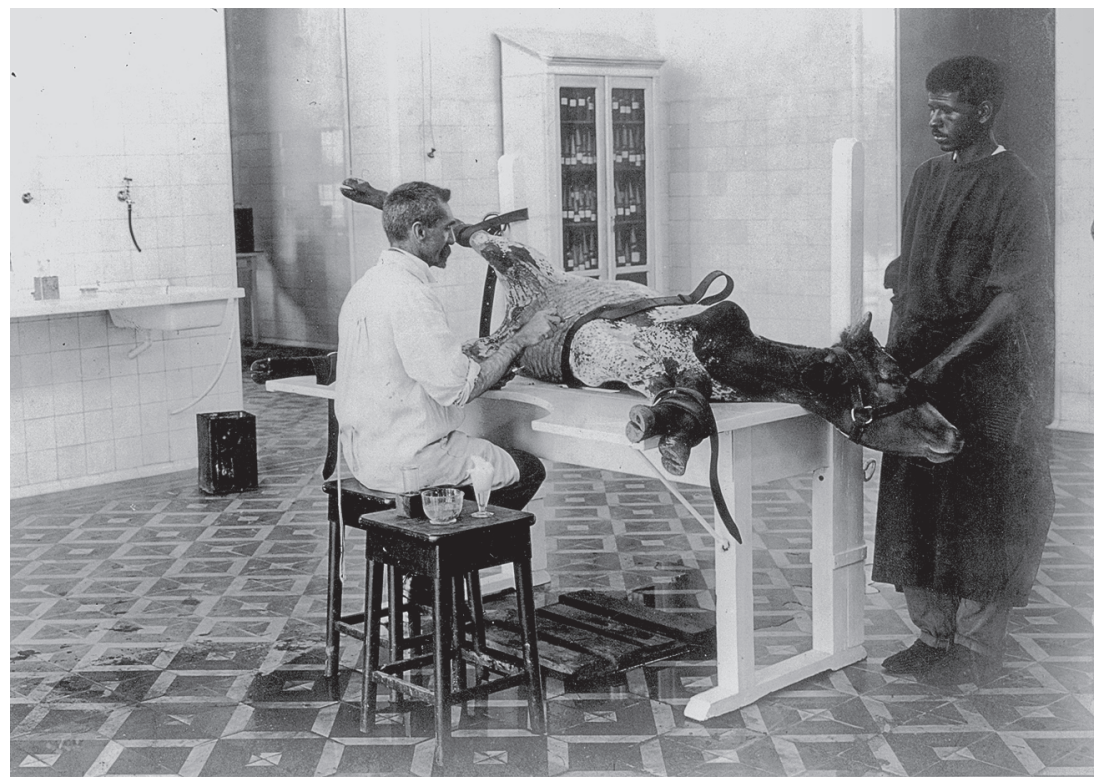

Fonte: Acervo da Casa de Oswaldo Cruz/Fiocruz. 


\section{Notas}

1 Jenner (1749-1823) nasceu em Beckley e concluiu seus estudos em Londres, retornando, em seguida, à sua cidade, onde iniciou experiências sobre a varíola. Inicialmente, seus trabalhos tiveram pouca repercussão, porém, após o sucesso de algumas experiências na Itália, Áustria e Alemanha, o governo inglês o reconheceu. Logo depois, iniciou-se ampla divulgação e difusão da vacina antivariólica por todo o mundo, sendo atribuída a ele a célebre descoberta.

2 Destacamos como estudiosos do assunto: François Jacob, Anne Marie Moulin, Michel Foucault, Salomon Bayet e Bruno Latour.

3 Sobre a utilização e difusão da prática da variolização, destacamos os estudos de Darmon (1986), Moulin (1996) e Chalhoub (1996).

4 A literatura corrente indica que a vacina humanizada foi introduzida no Brasil em 1804 pelo marechal Caldeira Brand Pontes (marquês de Barbacena), que enviou a Lisboa alguns escravos e um especialista ('facultativo') a fim de transmiti-la de 'braço a braço' até a Bahia, de onde foi da mesma forma trazida para o Rio de Janeiro ainda em 1804. Quanto ao uso da variolização no Brasil, esta não constitui uma questão para nós. Indicamos o trabalho de Sidney Chalhoub: Cidade Febril: cortiços e epidemias na Corte Imperial (1996).

5 Detectamos essas discussões por meio da análise de publicações da época, principalmente dos Anais da Academia de Medicina, de teses da faculdade de medicina e relatórios dos órgãos oficiais e periódicos.

6 Na tentativa de sistematizar o encadeamento factual de questões que envolvem a institucionalização da vacina antivariólica, elaboramos uma 'cronologia' sobre o assunto (ver Anexos 1 e 2). 